HORIZON 7 (1) 2018 : I. Research : V. Grahovac : 32-56

ФЕНОМЕНОЛОГИЧЕСКИЕ ИССЛЕДОВАНИЯ • STUDIES IN PHENOMENOLOGY • STUDIEN ZUR PHÄNOMENOLOGIE • ÉTUDES PHÉNOMÉNOLOGIQUES

https://doi.org/10.21638/2226-5260-2018-7-1-32-56

\title{
THE TENACITY OF "VICIOUS CIRCULARITY" IN KANT AND HUSSERL: ON TRANSCENDENTAL DEDUCTION AND CATEGORIAL INTUITION
}

\section{VEDRAN GRAHOVAC}

$\mathrm{PhD}$ in Philosophy.

University of Guelph, Department of Philosophy.

ON N1G 3E6 Guelph, Canada.

E-mail:vgrahovac@gmail.com

In this paper, I explore the strategy of circularity employed by Kant and Husserl in their treatment of categoriality. I focus on the relation between transcendental and metaphysical deductions in Kant's Critique of Pure Reason, and on the problem of "epistemic foundationalism" and categoriality in Husserl's Sixth Logical Investigation. I propose that the strategy of circularity is manifested through the peculiar self-enclosure of the categories of transcendental deduction vis-à-vis metaphysical deduction (Kant) and categorial intuition vis-à-vis sensuous intuition (Husserl). Although it is usually regarded as a deficient and damaging occurrence in argumentation, circularity appears to be a crucial component in the analysis of both thinkers. The analytical realms recognized by both these thinkers, is acknowledged as continually dependent upon the self-evidential "contingency" of the realms they are supposed to hierarchically overarch. The strict separation between the transcendental and phenomenological realms and their addressees appears to be founded on mutual circularity, where the relation between investigator and investigated extends beyond their separation and reconciliation. Both Kant and Husserl, through the circular relationship with empiricism-rationalism and psychologism radically re-articulated the logic-ontology and founding-founded polarities.

Key words: Kant, Husserl, circularity, categoriality, categorial intuition, metaphysical deduction, transcendental deduction.

(C) VEDRAN GRAHOVAC, 2018 


\title{
УСТОЙЧИВОСТЬ «ПОРОЧНОЙ ЦИРКУЛЯРНОСТИ» В ТРАНСЦЕНДЕНТАЛЬНОЙ ДЕДУКЦИИ КАНТА И КАТЕГОРИАЛЬНОЙ ИНТУИЦИИ ГУССЕРЛЯ
}

\author{
ВЕДРАН ГРАХОВАЦ \\ Доктор философии. \\ Гуэльфский университет, департамент философии. \\ ON N1G 3E6 Гуэльф, Канада. \\ E-mail:vgrahovac@gmail.com
}

В данной статье исследуется стратегия циркулярности, используемая Кантом и Гуссерлем в их трактовке категориальности. В центре внимания - взаимосвязь между трансцендентальными и метафизическими выводами в Критике чистого разума Канта, а также между проблемой «эпистемического фундаментализма» и категориальностью в Шестом Логическом Исследовании Гуссерля. Я предполагаю, что стратегия цикличности проявляется в своеобразном само-приложении категорий трансцендентальной дедукции по отношению к метафизической дедукции (Кант) и категориальной интуиции по отношению к чувственной интуиции (Гуссерль). Несмотря на то, что циркулярность обычно рассматривается как недостаточное и даже разрушительное для аргументации обстоятельство, она, по-видимому, является важным компонентом в анализе обоих мыслителей. Окружающая саму себя «чистота» аналитических сфер, учреждаемая этими мыслителями, понимается как постоянно зависящая от само-очевидной «случайности» этих сфер, над которыми они должны установить иерархическое доминирование. Строгое разделение между трансцендентальной и феноменологической сферами и их адресатами, по нашему мнению, основано на взаимной циркулярности, когда отношения между исследователем и исследуемым выходят за рамки их разделения и согласования. И Кант, и Гуссерль радикально переосмыслили логико-онтологические отношения и основывающиеся на них полярности через круговую (циркулярную) взаимосвязь с эмпиризмом-рационализмом и психологизмом.

Ключевые слова: Кант, Гуссерль, циркулярность, категориальность, категориальная интуиция, метафизическая дедукция, трансцендентальная дедукция.

\section{INTRODUCTION}

Both Kant and Husserl expand the scope of their philosophical analysis with an eye to the self-regulation of their own concepts. Every newly introduced investigative realm unfolds through the recognition of the results accomplished within its succeeding and preceding analytical level. The newly introduced theme is related to the other components of the analysis through its self-enclosure, while, in a peculiar way, it either enacts or restates the analytical results delivered by these other components. The systematic unity or methodological connection between concepts in Kant and Husserl is established through the constancy of the self-unfolding of these concepts. To show this, I primarily focus on the tables of judgments and categories in Kant's 
Critique of Pure Reason, as well as on the issues of foundationalism and categoriality in the Sixth Investigation of Husserl's Logical Investigations. I suggest a Husserlian reading of Kant by pointing out the dynamics in the excessive circularity of the seemingly static architectonics of Critique. Furthermore, I try to reversely apply a Kantian "static" circularity to the analysis of Husserl's phenomenological dynamism, as it is manifested in the concept of epistemic essence.

My aim is to demonstrate Kant's insistence on both, namely, the "backward reference" of any particular heading and moment within the table of judgments and the "self-referential" specificity of the table of judgments in its mutuality with the table of categories. The third moment and fourth heading do not simply play a mirror-like role, where the preceding two steps can be fully reflected through the undisputable authority of the third, reconciliatory instance. Rather, every particular moment and heading necessitates the completeness of the table of judgments and categories through the process of its backward-reference.

In chapter six of the Sixth Logical Investigation, which is concerned with the categorial intuition, Husserl introduces the notion of epistemic essence, which, constituted in categorial form and sensuous stuff, complicates the structure of intentional essence from the Fifth Investigation. Husserl manages both to further sharpen the analytic specificities of the epistemic and intentional essence and, at the same time, to maintain the possibility of their mutual actualization and re-articulation, but, "this time", within the realm of a new "epistemic level" - categorial intuition. The difference between categorial and sensuous intuition lies in the fact that categorial intuition obtains what is documented in it, not what is presented in it, thereby securing its ideality through its self-enactment. The intention fulfillment illuminates the specificity of intuited object by exhibiting its own elucidatory role.

\section{EXPOSITION AS AN EXHIBITION OF THE LOGICAL FUNCTIONS AND THE PURE CONCEPTS OF UNDERSTANDING}

In this part of my paper I focus on the First Book of the Transcendental Analytic, particularly on the table of judgments and the table of categories. Kant suggests a peculiar relation or even an argumentative unity between the table of judgments and the table of categories while insisting on the distinction between these two sections. This analysis reveals that the groundwork of the Critique is reflected in its procedural character, which is exhibited as a self-accomplishing of its thematic units. The legitimacy of the position of tables as nexuses and points of overview is confirmed through their self-exhibition. My intention is to illuminate Kant's strategy, as exercised in the 
following section of the Transcendental Analytic (more precisely, the Analytic of Concepts), in the Transcendental Aesthetics, and in some passages from Prolegomena to Any Future Metaphysics:

The same function that gives unity to the different representations in a judgment also gives unity to the mere synthesis of different representations in an intuition, which, expressed generally, is called the pure concept of understanding. (Kant, 1998, 211, A $79 /{\text { B } 105)^{1}}^{1}$

But how this peculiar property of our sensibility itself is possible, or that of our understanding and of the apperception which is necessarily its basis and also that of all thinking, cannot be further analyzed or answered because it is of them that we are in need for all of our answers and for all our thinking about objects. (Kant, 1977, $\$ 36,318-319)^{2}$

There are many laws of nature that we can only know by means of experience; but conformity to law in the connection of appearances, i.e., nature in general, we cannot discover by any experience, because experience itself requires laws which are a priori at the basis of its possibility. (Kant, 1977)

I propose the following interpretation of the above-quotations: the strategy of delineation of the realm of purity in the forms of intuition is the same strategy that is employed in the delineation of the pure forms of understanding. This means that the pure forms of intuition and understanding are introduced through their reference to their own regulatory capacity, as indicated in the second quotation. The regulatory role that is assigned to the pure forms of the capacities of reason defines their own composition. The "as if composition" unfolds in the following manner: if there is something that organizes our experience through the peculiar architectonics of its pure forms, then that organizing principle needs to be distinguished as a capacity(ies) of pure reason. In other words, the pure forms of the capacities of reason are distinguished exclusively through their capacity to regulate what is in need of such regulation. Kant, for example, explicitly states that we may "only judge an understanding

Unless otherwise indicated, emphasis in italics is mine throughout the essay.

2 Some emphasis is mine. Cf. Lorenz Krüger $(2005,29)$. Krüger also quotes the following reflections from Kant's letter to Herz on May 26 $6^{\text {th }}, 1789$ (XI 51): "But we are absolutely unable to explain further how it is that a sensible intuition (such as space and time), the form of our sensibility, or such functions of the understanding as those out of which logic develops are possible; nor can we explain why it is that one form agrees with another in forming a possible knowledge. For we should have to have yet another manner of intuition than the one we have and another understanding with which to compare our own and with which everyone could perceive things in themselves. But we can only judge an understanding by means of our own understanding, and to it is, too, with all intuition" (Krüger, 2005, 29). 
by means of understanding" (Kant, 1977, 29). The means of understanding become prominent precisely in the application of understanding to what it regulates, so to speak. Further, the impermeable purity of the forms (of intuition and understanding) is always contrasted with the realm of experience these forms are supposed to regulate. In other words, the pure forms of intuition and understanding are necessitated, in their purity, by the density of the experiential contingency. Furthermore, as the pure forms of understanding and intuition are established through the reference to their own regulatory activity these forms are architectonically related to each other through their mutual contrast. We can suggest that the thematic development of the Critique, in its self-enclosing layout, has a chain-like rather than a pyramidal-hierarchical appearance.

The lawfulness of self-grounding makes the field of transcendental logic distinctive in comparison to the jurisdiction of general logic (regardless of whether this logic is pure or applied). Thus, the logic, which does not "abstract from all content of cognition", would "concern the origin of our cognitions of objects insofar as that cannot be ascribed to the objects" (Kant, 1998, 196, A 56/B 80). This peculiar activity of grounding our cognitions of objects is able to determine "the origin, the domain, and the objective validity" (Kant, 1998, 196, A 57/B 81) of the pure cognition of reason, and it is called transcendental logic. We determine that one cognition is a priori transcendental (the cognition which does not depend on, but which grounds the possibility of experience) not only by stating the apriority of certain cognition, but also by showing "that and how certain representations (intuitions or concepts) are applied entirely a priori, or are possible (i.e., the possibility of cognition of its use a priori)" (Kant, 1998, 196, A 57/B 80)3. It is important to note that the expressions "that" and "how" do not refer to the question: "Why is this a priori transcendental cognition possible in reference to some higher argumentative ground?" (or to the goal which needs to be achieved once this a priori transcendental cognition is employed). To the contrary, what Kant wants to "achieve" with these terms is to emphasize the unbreakable bond between the definition and the application of a priori forms of cognition. This is the reason why Kant mentions application of the pure forms of cognition before their possibility, and also the reason why we might define an application of pure cognition as its possibility. What is important for Kant is the activity that "belongs only to the critique of cognitions and does not concern their relation to their object" (Kant, 1998).

In the first section of the "Clue Chapter", Kant suggests that, as much as "sensible intuitions are grounded on sensibility", so too are concepts "grounded on the

3 Some emphases are mine. 
spontaneity of thinking" (Kant, 1998, A 68/B 93). We can easily read this sentence in the following way: as much as the apriority of intuition has its own power and capacity, so too is the apriority of the understanding grounded in the indisputable activity of its own unfolding. In other words, the pure forms of intuition regulate experience through the perpetual accentuating of their own power to constrain the reason within the context of their jurisdiction. Similarly, the pure forms of understanding ground logical operations and experience that is available through understanding, while limiting the reason itself within the context of their own regulatory capacity. Since concepts rest on the "unity of the action of ordering different representations under a common one" their only purpose is to be used by the understanding, which makes "no other use of these concepts than that of judging by means of them" (Kant, 1998, A 68/B 93). Self-referentiality is also visible in the clarification of the concept, which "is therefore a concept only because other representations are contained under it by means of which it can be related to object" (Kant, 1998, A 69/B 94). The concept is defined as a mediator and an organizing thread of the representations since every representation is designed to be subsumed under another one through the guidance of the concept. Conversely, only because the presentations are predestined to be organized under the concept, are they supposed to be subsumed under it. This circularity is clearly stated with regard to the definition of mediate judgments. In other words, the judgment's lack of immediacy is the main condition of the systematic employment of judgments. We can understand why the definition of understanding must be introduced as its necessary employment of judgments and concepts, which are, themselves, employed in order to illuminate the notion of the power of understanding as such, if we recall the notions of mediacy and the higher representation as an orientating point. Understanding can be delineated not only as the faculty of judging, but also as the faculty of the co-composition between concepts and presentations through judging. This is why Kant states that the "functions of the understanding can therefore all be found together if one can exhaustively exhibit the functions of unity in judgments" (Kant, 1998).

Lorenz Krüger, in his essay "Did Kant Want to Prove the Completeness of his Table of Judgments?", suggests that Kant, in his attempt to oppose the traditional scholastic technique of conceptual analysis, actually developed the strategy of the "'analysis of the faculty of the understanding itself' which is supposed to 'analyze the pure use ( $s c$., of the understanding) in general", whereby "only an analysis of the pure use of the understanding could establish something about the completeness of the table of judgments" (Krüger, 2005, 23). The legitimation of this process is possible simply through the listing of the headings and the moments of the table of judgments by 
"placing [them] in front of our eyes", where the completeness of the table of judgments can only appear by referring to the idea of the unity of understanding, which is "a demarcating criterion" (Krüger, 2005, 31) The legitimation of the whole or the unity of the system (in this case, the unity of understanding in the completeness of the table of judgments) is achieved through its demarcating self-exhibition, which culminates in "systemacity and completeness" (Krüger, 2005, 30). Krüger refers here to the following passage from the Critique: "The functions of the understanding can therefore all be found together if one can exhaustively exhibit the functions of unity in judgments. The following section will make it evident that this can readily be accomplished" (Krüger, 2005, A 69/B 94). Krüger emphasizes the expression "vor Augen stellen" from the German original, and quotes the previous passage in the following manner: "But that this (sc., exhaustively presenting functions of unity of judgments) can readily be accomplished, the following section will place before our eyes (vor Augen stellen)" (Krüger, 2005, 31, A 69/B 94). Although Guyer's translation does not closely follow the German original, it is still especially suggestive, because it emphasizes that the exhaustive exhibition of the functions of unity in judgments needs to be accomplished in an evident manner. Guyer uses the word "evidence" and significantly contributes to the clarification of the connection between Kant's "scientifico-metaphysical" justification and the discourse of pure obviousness and announcement. In this sense, the difference between evidence and self-evidence appears to be crucially blurred, and this is accomplished through the mutuality of limiting and expansive tendencies in the Critique. However, it is important to take a look at the German original, because we realize that the term "accomplishment" or, to use a better word, "execution" (bewerkstelligen) is, in fact, significant for the exhaustive exhibition (vollständig darstellen), whereas one term stands for the other two and vice versa: „Die Funktionen des Verstandes können also insgesamt gefunden werden, wenn man die Funktionen der Einheit in den Urteilen vollständig darstellen kann. Daß dies aber sich ganz wohl bewerkstelligen lasse, wird der folgende Abschnitt vor Augen stellen“ (Kant, 1968, 111, A 69/B 94)

4 We should also recall the following observation by Brandt: "The question as to the systematic coherence of the table of judgments, necessary for acquiring the concepts of the understanding, is answered by the passage that introduces, presents, and explains the table of judgments. Everything is there and requires no hermeneutic question about essences" (Brandt, 1995, 41). I tend to see this statement as a clear delineation of the necessity for circular argumentation in Kant's construction of the language and method of the Critique, although Brandt, overall, attacks the notion of circularity in the argumentation of Kant's interpreters. Here I have in mind especially his attacks on Klaus Reich's tendency to ground and explain the table of judgments through Transcendental Deduction, in reference to which Brandt writes the following: "a 'system' is presupposed of which it was not shown that it was not developed with an eye toward the previously determined result" (Brandt, 1995, 27). 
Kant delineates the table of forms of understanding through the logical functions of the understanding in judgments. He isolates four headings or titles, each of which is branched through three moments: quantity (universal, particular, singular), quality (affirmation, negation, infinity), relation (categorical, hypothetical, disjunctive) and modality (problematic, assertoric, apodictic). The Kantian novelty regarding the "customary technique of the logicians" (Kant, 1968, A 71/B 96) is in the introduction of the third moment in a heading. Kant differentiates his own project from the one undertaken within the prevailing logical tradition already in the first heading (quantity), by declaring the specific role of the moment of singularity. He even commends the results of the logical tradition according to which singular judgment might have been operationalized as a universal. The fact that singular judgments do not have a domain of their own does not mean that they cannot be arranged in the same way as universal judgments, meaning that the concept in this case would be a "generally valid concept with a domain with the predicate applying to the whole of what is signified" (Kant, 1968). What is important from the point of view of transcendental logic, however, is the status of the singular judgment in comparison to the universal, within the working frame of the heading $(\text { Titel })^{5}$ of quantity. Kant's only way to introduce

Therefore, the "systematic coherence" of the table of judgments can be delivered only as the specificity, mutuality and purposiveness of (the order of) its elements. The construction of the table of judgments is not made in order to serve, or to stand as, the ordering principle as such; namely the creating of the table of judgments is at the same time their ordering.

5 Reinhardt Brandt $(1995,82)$ in The Table of Judgments: Critique of Pure Reason A 67-76/B 92101 directly emphasizes juridical aspects of the terms Titel and Momente, by referring to Kant's Metaphysics of Morals. He quotes Kant's statements that since "we have found the title of acquisition in an original community of the earth (VI 286) [...] the moments (attendenda) of original acquisition are thus [...] (VI 258)" and also, from the draft to Metaphysics of Morals, where he characterizes categories as "the acquisition of right" (XXIII 220). In this context, Brandt even mentions Baumgarten, and his concept of moments as attendenda to which we direct our attention or "attentio", and concludes that the concept of place in the context of table of judgments "refers to a legalistic context" (Brandt, 1995, 82). A bit earlier in his book, Brandt asks the following: "The table of all functions of the understanding makes it possible to determine 'the place' of every pure concept of understanding. Thus, the table of judgments is the topology for the pure functions of the understanding. The question is: How can these topoi be exhaustively acquired?" (Brandt, 1995, 48). Since Brandt notices that Kant uses the terms heading and title as synonyms with that of category in his Reflection 4672 (1773-75), it would be good to take a brief look at some parts of this reflection. Kant here directly connects the notions of place-topoi-ground and rule/process within the same argumentative-operational frame: "First there must be certain titles of thought, under which appearances can be brought in themselves: e.g., whether they are regarded as magnitude or as subject or as ground or as whole or merely as reality(figure is no reality). On this account I will not regard whatever I want in the appearance as either subject or predicate, rather it is determined as subject or respective as ground. [...] In order for appearances to belong to or be determined in accordance with certain 
the specificity of the singular judgment is through its own instantiation (with regards to cognition in general, on which Kant is focused here), where "with respect to the quantity it has in comparison with other cognitions, then it is surely different from generally valid judgments (judicia communia), and deserves a special place in a complete table of the moments of thinking in general (though obviously not in that logic that is limited only to the use of judgments with respect to each other)" (Kant, 1998, 207). Kant distinguishes between singular and universal judgments by suggesting that the singular judgment has to be special "surely", and that it is evident and justified in its own capacity to be a distinct and pure form of understanding. The question "Why is it that we have this state of affairs?" is transformed into the question of "How is this particular case of singular judgment exhibited, or how is its regulatory capacity unfolded?"

We notice the same self-exhibiting strategy in the heading of quantity, where Kant declares that the affirmative, infinite and negative judgments have to be differentiated from the point of view of transcendental logic, because these judgments, in principle, are concerned with the value or content of logical judgments instead of their pure form (which is the jurisdiction of general logic). Kant emphasizes that the only difference between transcendental and general-logical aspects of the proposition "The soul is non-mortal" is reflected in a way in which this proposition, as an infinite judgment within the frame of transcendental logic, legitimizes its jurisdiction:

\begin{abstract}
Now since that which is mortal contains one part of the whole domain of possible beings, but that which is undying the other, nothing is said by my proposition but that the soul is one of the infinite multitude of things that remain if I take away everything that is mortal. But the infinite sphere of the possible is thereby limited only to the extent that that which is mortal is separated from it, and the soul is placed in the remaining space of its domain. But even with this exception this space still remains infinite, and more parts could be taken away from it without the concept of the soul growing in the least and being affirmatively determined. In regard to logical domain, therefore, this infinite judgment is merely limiting with regard to the content of cognition in general, and to this extent it must not be omitted from the transcendental table of all moments of thinking in judgments, since the function of understanding that is hereby exercised may perhaps be important in the field of its pure a priori cognition. (Kant, 1998, A 76/B 101)
\end{abstract}

rules, it is necessary that they be represented as belonging under one or another function of them. Thereby do they become determinate objects of thoughts; otherwise there is nothing in their relations (for sensations are not thoughts) that makes them thinkable for the understanding" (Kant, $2005,153-154)$. If we follow Kant in this reflection, is it perhaps possible to conclude that the only way we can accomplish the final acquisition of the ground (or the verdict) is by constantly looking back at the process of this acquisition as such. Therefore, the legal-epistemological place that needs to be reached is the process of its reaching for as such. 
It is clear that the immortality of the soul is defined as the inability of the understanding, in this peculiar case, to determine the soul as anything beyond its non-mortal designation. Its immortality is proportional to the amount of the mortal aspects that can be "taken away of it" without violating the legitimate space of its transcendental-logical, quantitatively infinite profile. The sphere of immortality is self-limited with an eye to the realm of mortality, and it gains its transcendental profile through this self-limitation. The transcendental expansion of the moment of infinity is based on its proneness for self-regulation. This self-regulation is the reflection of the capacity of the moment of infinity to remain alert to the contingency it oversees. Conversely, this overseen experiential contingency, through its habitual lack of the capacity to regulate itself, calls for its own purification. The infinity's persistence in perpetual distinction from the realm of mortality, as it regulates this realm, resembles the work of a peculiar kind of self-assurance. The only novelty of the table of categories vis $\dot{a}$ vis the notion of self-assurance is that, in the case of the above-mentioned moment of quantity, the self-assurance is the exclusive mode of self-establishment.

The same type of self-regulatory approach is applied in the case of the heading of relation where, in the addition to the moments of categorical (relation between subject and predicate) and hypothetic (relation between ground and consequence), the third moment of disjunctive judgment is distinguished. This moment of judgment contains the "relation of logical opposition insofar as the sphere of one judgment excludes that of the other, yet at the same time the relation of community, insofar as the judgments together exhaust the sphere of cognition proper" (Kant, 1998, A 73-74/B 99). Kant further writes that "it is therefore a relation of the parts of the sphere of a cognition where the sphere of each part is the complement of that of the others in the sum total of the divided cognition, e.g., 'The world exists either through blind chance, or through inner necessity, or through an external cause" (Kant, 1998). The "true cognition in its entirety" is achieved through the application of disjunctive judgment within "a certain community of cognitions, consisting in the fact that they mutually exclude each other" (Kant, 1998). In the heading of relation, we witness more clearly that the distinction of each moment does not simply add up to the definition of the heading, but the heading as such is defined through the introduction of a third moment, namely disjunction. The third moment appears to be not a simple mediating instance between the other two moments, but an expression of their relation in isolation from each other (within their respective realms of purity). In the initial description of disjunction, Kant observes that the heading of relation is obtained between "the cognition that is divided and all of the members of the division" (Kant, 1998, A 73/ B 98). If we state that infinity could be portrayed as a peculiarly negative affirmation, 
and that the singularity is the universality which is particularized, then we can infer that the disjunction is a categorical hypothesis.

The establishment of headings and moments, whose legitimacy is demonstrated through its own processing culminates in the installment of modality. Kant gives a special status to the heading of modality in comparison to the other three headings, by providing it with the ability to "contribute nothing to the content of the judgment (for besides quantity, quality, and relation there is nothing more that constitutes the content of judgment), but rather [to concern] only the value of the copula in relation to thinking in general" (Kant, 1998, A 74/B 100). Kant states that the heading of modality is necessary because the jurisdiction of the other three headings (concerning the content of judgment) is exhaustively determined. We can also say that the definition of what is supposed to have a certain jurisdiction is exhausted through the enumeration of the three headings. The space of jurisdiction of modality is secured in a static and "implicit" manner: since the lawful field of content is clearly defined, the only field in need of further arrangement is the field of form. That the modality is not concerned with content is clear from the following example: although the proposition "There is a perfect justice" can obviously be false, that does not concern the realm of modality, according to which this proposition can only have a problematic significance (although the implication is assertoric, this judgment serves exclusively as a problematic, because it is "thought of only as an arbitrary judgment") (Kant, 1998, B 100/A 75). Just as the problematic proposition is focused only on logical possibility, so too is the assertoric judgment focused on the logical actuality (of truth). Similarly, the apodictic judgment "thinks of the assertoric one as determined through these laws of the understanding itself, and as thus asserting $a$ priori, and in this way expresses logical necessity" (Kant, 1998, A 76/B 101). The third moment, in the case of all headings, is not just purely added from some external source, but it is proposed as a reflection of the relation in difference between the two "preceding" moments. Kant not only acknowledged the findings of traditional logic through the recognition of the first two moments, but also disclosed the self-propelling declarativeness within which these moments were created. The third moment simply re-emphasized the self-enclosure in the instantiation of the first two moments. Once the delineation of the self-sufficiency of each moment in relation to each other is completed, we realize that the division of the categories "transcends mere logic".

6 We should recall here the following observation by Brandt (1995): "Common to each of the third moments is the relation of a given individual to the whole in which the individual is located. Located: space clearly serves as a foil for comprehending the specifically logical relation and at the same time the moment in the relation that transcends mere logic. The first two moments can perhaps be taken 
If we come back to the Third Section of the "Clue Chapter," we see that Kant uses the same strategy of "equal" (not only in relation to potential and strength, but also to argumentative structure) profiling regarding the relation between the tables of judgment and categories:

The same understanding, therefore, and indeed by means of the very same actions through which it brings the logical form of a judgment into concepts by means of the analytical unity, also brings a transcendental content into its representations by means of the synthetic unity of the manifold in intuition in general, on account of which they are called pure concepts of the understanding that pertain to objects a priori. (Kant, 1998, A 79/B 105)

The same understanding (derselbe Verstand) (Kant, 1968, 118, A 79/B 105), or more precisely, the same strategy involved in bringing the logical form of judgments into concepts, can be traced both in the table of judgments and the table of categories. The power of the careful delineation of main constitutive points is entirely the same in the sections of the Critique concerned with both type of unities. The "only" crucial and important structural difference is in the steps, the first of which, as Lorenz Krüger notes, leads "to the table of judgments, and [which] is simply repeated, in a second step, as it were, only in another light because the same function (Kant, 1968, A 79/B 104) of the understanding is revealed in a new respect with regard to a further given, the manifold of intuition (which transcendental logic has "lying in front of itself a priori” (Kant, 1968, A 76/B 102))" (Krüger, 2005, 28)7. The peculiarity of transcendental logic is that it teaches us "how to bring under concepts not the representations but the pure synthesis of representations" (Kant, 1968, A 78/B 104). This, of course, stands in complete contrast to general logic, which is concerned only with the transformation of the representations into concepts analytically, regardless of how these representations are given. Kant does not say, unconditionally, that the jurisdiction of one step is "epistemologically" more valuable than the other, but he decisively delineates the strategic importance and the necessity of each of these realms ${ }^{8}$. Kant therefore comes

as positions and their merely logical negations or reversals: The negation of 'All' leads to 'Some', the negation of affirmation to negation; the reversal of the direction of determination in moving from categorical judgment to hypothetical judgment. In the third moment this internal reference is abandoned, and the judgment is related to a presupposed totality of content" (Brandt, 1995, 78).

7 Further in the text Krüger states the following: "Transcendental idealism is thus immediately connected to the indispensability of 'metaphysical' arguments. Kant's standpoint requires that the synthetic unity of apperception is indeed the highest point of philosophical reflection on our knowledge, but cannot be a source of speculative proofs" (Krüger, 2005, 42).

8 Thus, for example, the peculiarity of the table of categories (and the Transcendental Deduction as such) lies in the fact that 1 ) the manifold of pure intuition needs to be given to us a priori (therefore, 
up with the table of categories which hosts "exactly as many pure concepts of the understanding, which apply to objects of intuition in general a priori, as there were logical functions of all possible judgments in the previous table: for the understanding is completely exhausted and its capacity entirely measured by these functions" (Kant, 1968, A 79-80/ B 105) $)^{9}$. The organizing principle in which these categories arise is, in fact, the way of their organizing and it bears the operative name of the "faculty of judging" (Kant, 1968, A 81/B 106). This is precisely the main difference between Kant and Aristotle, of whom Kant says that he was exposed to the "haphazard search for pure concepts" and that he "rounded them up as he stumbled on them" (calling them categories) (Kant, 1968, A 81/B 107). This was possible only because Aristotle did not use Kant's concept of the organizing principle, which not only orders the elements of the system, but is also expressed in the self-regulating distinctiveness of these elements. That the organizing principle has merely the significance of the demarcation of the elements of the system is clear from the following observation:

I deliberately spare myself the definitions of these categories in this treatise, although I should like to be in possession of them. In the sequel I will analyze these concepts to the degree that is sufficient in relation to the doctrine of method that I am working up" (A 82-83/ B 109) [...]. For that this table is uncommonly useful, indeed indispensable in the theoretical part of philosophy for completely outlining the plan for the whole of a science insofar as it rests on a priori concepts, and dividing it mathematically in accordance with determinate principles, is already self-evident from the fact that this table completely contains all the elementary concepts of the understanding, indeed even the form of a system of them in the human understanding, consequently that it gives instruction about all the moments, indeed even of their order, of a planned speculative science, as I have elsewhere given proof (A 83/B 109-110). (Krüger, 2005)

It is indicative that Kant emphasizes the terms "moments", "dividing", and "order", whereby one can conclude that the order as such is nothing but the division of moments. Kant's observation that this organizing principle already contains "all the

we need to be confident in the apriority of the source of cognition), 2) the synthesis of this manifold needs to be accomplished by means of transcendental imagination and 3) we need to have the concepts that, in a separate cognitive act, give to this synthesis the pure synthesis of unity (which is later in the text collapsed into transcendental apperception).

9 Kant also says that the specificity of the table of categories lies in the fact that it simply uses what is already delivered by the table of judgments. Thus he writes that "In any case, from the little that I have here adduced it becomes clear that a complete lexicon with all the requisite definitions should be not only possible but even easy to produce. The headings already exist; it is merely necessary to fill them out, and a systematic topic, such as the present one, will make it easy not to miss the place where every concept properly belongs and at the same time will make it easy to notice any that is still empty" (Kant, 1968, A 83/ B 109). 
elementary concepts", that it possesses "even the form of the system of them" and that instructs "about all the moments", and "even of their order", directly suggests that its completeness is embodied in the table. We can conclude that the construction of the system (the table of categories in this case), which is simultaneously its self-application, is the most obvious manifestation of the ordering principle as such. The strategy executed here is one of self-assurance and self-sufficiency, and it consists in the achievement of the respect for the unquestionable specificity and the necessarily belonging in difference of the parts of the system - which is, therefore, the same strategy found in the table of judgments.

Giorgio Tonelli suggests that Kant was inspired to pursue an independent and self-grounding discipline of metaphysics by looking at the work of Jacob and Christian Thomasius. He observes that the intention for the establishment of the independent philosophical discipline actually has a ground in the major crisis of sixteenth- and seventeenth-century Aristotelianism. This crisis culminated in a debate about which discipline - whether logic or metaphysics - or, perhaps, something "beyond" both of these branches should deal with the issues such as categories and first principles ${ }^{10}$. Tonelli points out that although Kant never aimed at the establishment of the independent theory of knowledge - which was "established only after Kant" (Tonelli, 1994, 168) - he was still influenced (via his teachers in Königsberg) by the attempts for the construction of the discipline, which would be independent, both, from logic and metaphysics ${ }^{11}$. Tonelli is furthermore convinced that this is directly reflected in

10 We can find an important historical overview and background of this problematic in sections 1623 of the second chapter, and earlier in sections 24-28 of the first chapter of Tonelli's Kant's Critique of Pure Reason Within the Tradition of Modern Logic. The continual conflict between medieval realism (according to which the categories are concepts expressing an order of being intrinsic to things) and nominalism (where the categories are the "concepts of the mental order which did not correspond to an order of things" (Tonelli, 1994, 165)) is a part of the complex debate concerning the disciplinary place (locus proprius) of discussions concerning supra praedicamenta or transendentalia, categories, praedicabilia or postpraedicamenta and first principles. Opinions differed and clashed about the question of which discipline suppose to host these discussions, namely whether that is metaphysics (philosophia prima) or logic. Attempt to solve this problem even led to the establishment of two special disciplines: noology (solving the "problems of the proper place for questions like the first principles, the origin of knowledge"(Tonelli, 1994, 167)) and gnoseology ("the study of what can be known (cognoscibile) qua tale, of the notion and possibility of knowledge, of the relationship between concept and thing represented, of abstraction, analogy, etc." (Tonelli, 1994, 168). Tonelli concludes that these attempts however failed and were not repeated again in the nineteen century.

11 These attempts were "a clear symptom of the instability of the situation, and contributed to the erosion of the borderline between logic and metaphysics" (Tonelli, 1994). 
Kant's separation of (and the confrontation between) transcendental philosophy and critique of pure reason ${ }^{12}$.

According to Tonelli, Kant might have found a special inspiration for designing of the Critique in the concept of "an instrumental discipline" (Tonelli, 1994, 173), which can be designated as a dictionary (the same concept which we find in the work of Jacob Thomasius). However, what the term dictionary in this case means "is a list of definition of terms, but not in alphabetical order" (Tonelli, 1994). Tonelli paraphrases Thomasius, and says that metaphysics, once deprived of natural theology, is "nothing but a dictionary which is attached, or subordinated to logic in the same way as a Latin dictionary is attached to grammar" (Tonelli, 1994) ${ }^{13}$. Tonelli further writes that "metaphysics is nothing but a dictionary of terms, useful in preventing error rather then in reaching the truth" and therefore it "cannot be separated from logic, in that it belongs to the theory of concepts" (Tonelli, 1994, 174-175). He also notes that Jacob and Christian Thomasius developed this peculiar type of nominalistic ontology, which is supposed to be "nothing more than a list of arbitrary definitions [which] amounts to reducing all general metaphysical concepts to human construction" (Tonelli, 1994, 176). As long as "particular language" provides us the ability to note and investigate certain regularities or just "matter of fact in a way which is adequate for our purposes, the knowledge it provides is valid" (Tonelli, 1994). It goes without saying that anything that might have been of interest to the investigator of ideal regularities, and which might have developed a tendency to go beyond this above-mentioned regularity, is not only unwanted but is also not allowed as such. This directly refers to our ability to see the terms of this language as the "real characters of the matter of fact in question" (Tonelli, 1994). Tonelli, by concluding that this terminological apparatus and instrument is nothing more than "a convention" (Tonelli, 1994), willingly or not, gives enormous strength and importance to the self-exhibiting potentials of the metaphysics. He thus illuminates the significance of the interconnection between the terms: usage, purposiveness, adequacy, and validity within the context of the Critique's self-demonstration.

12 Tonelli stresses that Kant had to make a clear distinction between "expounding the whole body of transcendental philosophy" and the critique of pure reason which establishes the "area of analytic knowledge which is required in order to found the principles of the synthesis a priori in their entirety", and whose aim is nothing but that of "correcting human knowledge" and providing "the touchstone for the validity or invalidity of all knowledge a priori" (Tonelli, 1994, 76).

13 Tonelli clarifies this statement, saying that the relationship between dictionary and grammar echoes the historical state of affairs, where the dictionaries (whether Latin or German) were either attached to grammar books, or contained one (Tonelli, 1994, 174). 
The carefully developed mechanism of the minute ramification of the parts of the system seems to have, in fact, no other role but to emphasize the tendency for the self-exhibition of the Critique of Pure Reason. It is important to understand that the canonic-organonic ${ }^{14}$ self-examination of the critique culminates in the Transcendental Analytic, especially in the section on the concepts of pure understanding. The setting of the ground of Transcendental Analytic, particularly in the Analytic of Concepts, which will provide the placement and operative-structural mutuality between the Transcendental and Metaphysical Deduction, has a dominantly self-exhibiting character and is historically introduced by Tonelli. Tonelli distinguished two traditions that developed in the aftermath of nominalism: one that can be traced from Gassendi to Locke and Hume, and another culminating in the work of Christian Thomasius. After making this distinction, Tonelli remarks that:

In his Transcendental Analytic, Kant produced his own ontological dictionary. Its terms, deprived of intrinsic metaphysical validity, are adequate to the elaboration of a valid metaphysics of nature and of morals, in so far as they correspond to universal and necessary functions of the human mind. As Thomasius and his followers had done, Kant separated this version of ontology from metaphysics. That is, he separated that part of the Critique of Pure Reason, which corresponded to transcendental philosophy, namely Analytic. He transferred it to logic, or more precisely, to the special logic of metaphysics, namely the Critique. Obviously, Kant's position is very distant from the two traditions mentioned above. But I think it is safe to assume that he found in the early Thomasian school a source of inspiration for a more adequate formulation of his own position trough the idea of an ontological dictionary. Its terms, albeit not conventional, are not expressive of any absolute truth, but, if properly used, can yield an adequate metaphysical knowledge of the human world. [...] we shall see (1) that the Critique as a whole is a methodology in a broad sense [...] and (2) that the special logic or organon of a certain science (in accordance with the Wiener Logik, where it is called technical logic) is supposed to contain among other things a list of all technical terms of method [...]. Now, Kant indirectly states in the Critique, referring at least to the Analytic of Concepts, that the latter is a vocabulary or dictionary (Wörterbuch), although incomplete (A 83/B 109). According to the Lectures on Philosophical Encyclopedia (1777-1780?), the whole Analytic of the Critique is a dictionary of pure reason. Therefore, we can conclude once more that (1) the notion of special logic as dictionary plus methodology stricto sensu, is virtually the same thing as

14 The circular character of the Critique of Pure Reason is visible in the following passage from the Critique: "Such a critique is accordingly a preparation, if possible, for an organon, and, if this cannot be accomplished, then at least for a canon, in accordance with which the complete system of the philosophy of pure reason, whether it is to consist in the amplification or the mere limitation of its cognition, can in any case at least some day be exhibited both analytically and synthetically" (Kant, 1968, A11-A12/B 25). Therefore, as long as it is successfully self-processed and efficiently exhibited as such, it is entirely irrelevant for an overall investigation, whether we should ascribe to the critique the character of an organon (ontological) or of a canon (logico-metaphysical). 
practical logic; (2) the Critique, being on the whole methodology in a broad sense, is one practical logic. (Tonelli, 1994, 91-92, some emphases are mine) ${ }^{15}$

In the opening sentence of the above quotation we witness the enacting of the circularity inherent to Kant's argumentation in the Critique where the validity and adequacy of the new metaphysics is re-confirmed through metaphysics' reference to its own universality. This self-demonstration is precisely what makes this metaphysics a "separate ontology", whose character is embodied in the peculiar dynamics of Transcendental Analytic. Therefore the peculiarity and significance of Analytic amplifies the procedural-disciplining character of the Critique, and makes the Critique of Pure Reason a special logic of metaphysics. The reason why the Thomasian school might be an inspiration for Kant lies in its emphasis on the self-regulatory aspect of "logic-as-metaphysics", whereby the propriety of the overall usage and self-application of the system is clearly countered with the potential for the expression of "any absolute truth". Precisely because of this, we can call the whole of Critique, being a peculiar exhibition of the self-processing methodology, a methodology "as a whole" and "in a broad sense". What is in fact practical about the distinctness of the Critique as a practical logic, is its exercise in its own regularity and lawfulness.

\section{HUSSERL'S CIRCULAR METHODOLOGY IN THE ESTABLISHMENT OF CATEGORIAL INTUITION IN THE SIXTH LOGICAL INVESTIGATION}

Husserl's transcending of the notion of synthetic unity within the realm of categorial lawfulness is carefully developed in the Sixth Logical Investigation as a radical criticism and further complexification of Brentano's notion of foundationalism. However, it is important to note that, despite the open criticism of Brentano's concept of inner consciousness and the clear traces of Bolzanian methodological influences, Husserl still enriches the methodological "pointillism" of the preceding investigations with an emphasis on the problem of self-evidentiality. In chapter six of the Sixth $\log$ ical Investigation, which is concerned with the notion of categorial intuition, Husserl focuses on the inner laws of ideal unities. The key question for Husserl in this investigation is not how things are united into one synthetical whole (in the sense of their addition), but rather how this unity is manifested within its categorial context.

15 In a sentence immediately following this reflection, Tonelli stresses the fact that "of course, the argument for this second conclusion presupposes the very plausible hypothesis that Kant in 1781 already had in mind what he wrote about technical logic in the Wiener Logik" (Tonelli, 1994). 
Husserl introduces the notion of epistemic essence, which, as a further expansion upon the notion of intentional essence (the co-composition of act quality and act matter), is constituted in (categorial) form and (sensuous) stuff ${ }^{16}$. Thus, instead of repeating the dynamics of fulfillment where the "meaning intentions of expressions" correspond to the "mere percepts" (Husserl, 2006, 273). Husserl is interested in the concept of fulfillment as a "parallelism" between meaning intentions and "certain connective or otherwise formational acts", which are the result of "the epistemic essence of our seeing, in which the apparent object announces itself as self-given" (Husserl, 2006) ${ }^{17}$. Husserl crucially portrays fulfillment not as a mere process of intentional correspondence between intending and intended acts, but as a constant tension built into the installation and parallelism between meaning intentions and perceptually founded (thus not perceptual) acts. The word "parallelism" not only emphasizes the phenomenological peculiarity of categorial form, but it furthermore preserves the results accomplished within the frame of intentional essence. Husserl further sharpens the analytic specificities of both phenomenological-descriptive levels: the epistemic and the intentional essence, while emphasizing their mutual actualization. Their mutual re-articulation occurs, "this time", within the complexity of the new epistemic level - categorial intuition. Thus, intuition in this context has an "essential relation to

16 Husserl avoids using the word matter here, because he does not want to confuse the notions of epistemic and intentional essence.

17 It is important to mention that the German original illuminates the tension built into the establishment of epistemic essence (in contrast to intentional essence) more directly, because Husserl, in the German original, stresses the importance of the realm of the categorial as an "as if" specificity. Therefore, the English translation reads "It may also be the case that the epistemic essence of our seeing, in which the apparent object announces itself as self-given, serves to base certain connective or relational or otherwise performative acts and that it is in such acts, performed on a basis of actual perception, that our expression, in respect of such changing forms, finds fulfillment" (Husserl, 2006). However, if we take a look at the German original, we clearly see the importance of the "as if" construct underlying the peculiarity of the categorial and strengthens the tension built into its operational "relation” with the sensuous realm: „Es kann ja auch sein, daß das erkenntismäßige Wesen des Sehens, in dem sich die erscheinende Gegenständlichkeit als selbst gegebene bekundet, gewisse verknüpfende oder beziehende oder sonstwie formende Akte begründet, und daß diese es sind, denen sich der Ausdruck mit seinen wechselnden Formen anmißt, und in denen er, hinsichtlich dieser Formen, als auf Grund aktueller Wahrnehmung vollzogen, seine Erfüllung findet" (Husserl, 1980, 133, emphases in bold are mine). It is clear that the expression finds its fulfillment in the epistemic essence as if (als $o b)$ it was the ground of actual perception. Therefore, the self-unfolding with which Husserl delineates the specificity of the categorial realm is even more emphasized, because the only difference between the categorial and the sensuous realms lies in the fact that the fulfillment within the realm of the categorial is performed with reference to the unfolding of this realm. This reflection implies that the achievement of fulfillment within the categorial is literally the same as within the sensuous, but it has an important modification: it is placed within the categorial context. 
expression and to its meaning"; this time, however, not as a "mere togetherness," but as a "unity of felt belongingness" (Husserl, 2006, 274) between general knowledge and intuition. The objective possibility of the new type of intention fulfillment is reflected in its ability to address the specificity of the intuited object by emphasizing its own elucidatory role. The intuition in the categorial context is characterized as an instance obtaining what is merely documented in it, not what is presented in it. Therefore, it is precisely the self-execution of categorial intuition, its continual emphasis on its own capacity for categorial elucidation, that makes its own universal reality ${ }^{18}$.

Husserl, while dealing with the notion of Being, clearly demonstrates the connection between the strategy of self-enclosure in the delineation of ideal lawfulness and a clear anti-Brentanist attitude, which is manifested in Husserl's sharp rejection of the psychologistic concept of inner consciousness. This is most obvious in Husserl's definition of Being as a notion, which is not somehow attached to an object. The Being has "no real (reales) internal feature, so also it has no real external feature, and therefore not, in the real sense, a 'feature' at all [...]. Being is as little a real constituent of some inner object as it is of some outer object, and so not of a judgment" (Husserl, 2006, 277-278). Husserl leaves the possibility of the thematizing of Being through the process of judging open. He does so, however, only under condition that the judging should not be understood as "merely judging-intentions connected with actual assertions, but [as] the fulfillments that in the end fit them completely" (Husserl, 2006, 279). Husserl does not accept that Being is reached "through reflection' on certain judgments" (Husserl, 2006), and makes the following statement:

Not in reflection upon judgments, nor even upon fulfillments of judgments, but in the judgments themselves lies the true source of the concepts State of Affairs and Being (in the copulative sense). Not in these acts as objects, but in the objects of these acts, do we have the abstractive basis which enables us to realize the concepts in question. And naturally the appropriate modifications of these acts yield just as good a basis [...]. If we are asked what it means to say that categorially structured meanings find fulfillment, confirm themselves in perception, we can but reply: it means only that they relate to

18 The context of the universality of intuition is clearly delineated in Husserl's reflection: "Where general thoughts find fulfilment in intuition, certain new acts are built on our percepts and other appearances of like order, acts related quite differently to our appearing object from the intuitions which constitute it. This difference in mode of relation is expressed by the perspicuous turn of phrase employed above: that the intuited object is not here itself the thing meant, but serves only as an elucidatory example of our true general meaning. But if expressive acts conform to these differences, their significative intention will not move towards what is to be intuitively presented, but towards what is universal, what is merely documented in intuition. Where this new intention is adequately fulfilled by an underlying intuition, it reveals its own objective possibility (or the possibility or 'reality' of the universal)" (Husserl, 2006, 275). 
the object itself in its categorial structure. The object with these categorial forms is not merely referred to, as in the case where meanings function purely symbolically, but it is set before our very eyes in just these forms. In other words: it is not merely thought of, but intuited or perceived. (Husserl, 2006, 279-280)

The progression of analytic complexification and subversion of the notion of presentational foundationalism reaches its peak in the circularity of categorial intuition. This time, although fully recognized, the results of the previous investigations (especially the Fifth Investigation) are turned into a matter of operational reference, thus becoming the material illuminated by the epistemic self-sufficiency of the categorial realm. Husserl states that, on this categorial "level", he is interested neither in the further expansion upon intentional essence nor in reflections upon the complexities of the process of fulfillment of judgments. He is plainly interested in the structural and operational self-reference of the judgments themselves, because this is the only thing that, according to him, can be our focus, especially once we want to understand the "abstractive basis which enables us to realize the concepts in question". Husserl never defines what abstractive basis "in fact" is outside of the need for realizing "the concepts in question". Even the possibility of defining this basis outside of its self-unfolding would severely miss the core of Husserl's intention here. Even though the fulfillment of categorial acts is confirmed in perception, the concept of perception here refers to the process where categorially structured meanings relate to "the object itself in its categorial structure" (Husserl, 2006) ${ }^{19}$. The reason why we cannot suggest the possibility of symbolic signification here (where the concept of meaning intention-meaning fulfillment is achieved on the level of symbolic reference to the object) lies in the fact that only through the categorial forms is the object simply set before our eyes (vor Augen gestellt) ${ }^{20}$ within the context of categorial synthesis.

19 Formal-structural similarities and operational-contextual differences between sensuous and categorial intuition are given through the example of aggregate: "If 'being' is taken to mean predicative being, some state of affairs must be given to us, and this by way of an act which gives it, an analogue of common sensuous intuition. The like holds of all categorial forms (or of all categories). An aggregate e.g., is given, and can only be given, in an actual act of assembly, in an act, that is, expressed in the conjunctive form of connection $A$ and $B$ and $C$... But the concept of Aggregate does not arise through reflection on this act: instead of paying heed to the act which presents an aggregate, we have rather to pay heed to what it presents, to the aggregate, it renders apparent in concreto, and then to lift the universal form of our aggregate to conceptually universal consciousness" (Husserl, 2006, 280, emphases in bold are mine).

20 „Der Gegestand mit diesen kategorialen Formen sei nicht bloß gemeint, wie im Falle einer bloß symbolischen Funktion der Bedeutungen, sondern es sei uns, in eben diesen Formen selbst vor Augen gestellt; mit anderen Worten: er sei nicht bloß gedacht, sondern eben angeschaut, bzw. Wahrgenommen" (Husserl, 1980, 143). Here we witness again the clear formal and contextual resemblances with the Kan- 
Husserl therefore refuses to talk about the synthetical act within the realm of categoriality as "if something had merely been shoved in between unchanged presentations, a bond which combined them in merely external fashion" (Husserl, 2006, 289). The universal self-sufficiency of the new analytic level is manifested precisely in its ability to shape the synthetic components anew, and not in a way that the object could "appear before us with new real (realen) properties" (Husserl, 2006). To the contrary, the object "stands before us as this same object, but in a new manner" (Husserl, 2006). This is why objectifying acts, which exist "purely 'on their own'", differ phenomenologically from "the same objectifying acts serving to constitute the terms of some relation or other" (Husserl, 2006).

The self-referring specificity of the categorial realm and its relation to the accomplishments of sensuous intuition is especially visible in moments when categorial intuition is countered with the notions of continuous and straightforward perception:

But the unification of these percepts into a continuous percept is not the performance of some peculiar act, through which a new consciousness of something objective is set up. We find, instead, that absolutely nothing new is objectively meant in the extended act, but that the same object is continuously meant in it, the very object that the part-percepts, taken singly, were already meaning [...]. The articulating acts and, taken in retrospect, the act we call "straightforward", are not merely experienced one after the other: overarching unities of act are rather always present, in which, as new objects, the relationship of the parts become constituted. [...] These two acts are not merely performed together, or after one another, in the manner of disjoined experiences; rather are they bound together in a single act in whose synthesis $\mathrm{A}$ is first given as containing $\alpha$ in itself. (Husserl, 2006, 285-287)

The concept and the achievement of straightforward perception (the act which grasps $\mathrm{A}$ as a whole in one blow) is neither dismissed nor enriched by the dependent moment that belongs constitutively to A, but is re-articulated in an entirely new manner, that is a manner manifested both through the acknowledgment of the straightforward or continuous perception and through the necessity to manifest its own operational self-grounding. We find the same constellation in the context of continual perception, which, once re-contextualized within the categorial act, "does not amount to the mere fact of temporal adjunction" (Husserl, 2006, 284). Thus "the series of

tian insight into the process of metaphysical deduction, where the exhaustive presentation of the functions of judgment is simply placed in front of our eyes: „Die Funktionen des Verstandes können also insgesamt gefunden werden, wenn man die Funktionen der Einheit in den Urteilen vollständig darstellen kann. Daß dies aber sich ganz wohl bewerkstelligen lasse, wird der folgende Abschnitt vor Augen stellen" (Kant, 1968, 111). 
individual acts rather has the character of a phenomenological unity, in which the individual acts are fused" (Husserl, 2006).

We clearly see that the founded categorial acts do not deliver a new type of objectivity, but that they make their contextualization of the relationship between parts universally objective. Thus, the "processual" self-reference of the categorial acts within their own realm of jurisdiction - is in fact the novel manner of synthetical achievement or of an objectifying act. The complexification of foundationalism and its accompanying tension(s) is particularly manifest in the following reflections on identity and categorial form:

\begin{abstract}
Identity itself is now made objective, the moment of coincidence linking our act-characters with one another, serves as representative content for a new percept, founded upon our articulated individual percepts. This brings to intentional awareness that what we now see and what we saw before are one and the same. [...] Our act of identification is in sober fact a new awareness of objectivity, which causes a new "object" to appear to us, an object that can only be apprehended or given in its very selfhood in a founded act of this sort. [...] Just as the object in straightforward perception directly confronts us, so too does the state of affairs in the act which names it, and so too does any categorically formed object. The gradual constitution of the object has been completed, as a finished object it becomes a term in a relation: it keeps, it seems, its constitutive sense quite unaltered. [...] In an act of abstraction which need not necessarily involve the use of an abstract name, the universal itself is given to us, we do not think of it merely in significative fashion as when we merely understand general names, but we apprehend it, behold it. Talk of an intuition and, more precisely, of a perception of the universal is in this case, therefore, well-justified. (Husserl, 2006, 285, 290, 292)
\end{abstract}

The obvious self-reference from the first part clearly aims to dismantle any possible attempts at defining an identifying act within the realm of categoriality as being a pure abstractive collecting grounded in the peculiar novelty of an abstractive superstructure. Had the realm of categoriality been conceived in this manner, then the categorial acts would have been mere transformations and enrichments of the preceding stages. Husserl sharply opposes this by emphasizing the uniqueness of the new analytic step of categorial intuition, which, although it clearly acknowledges the results of the preceding synthetical activity, still radiates with its own operational significance and uniqueness. Just as the synthetical achievements of the preceding phases refer to their own initiation and unfolding, so do the categorial acts refer to the specificity of their own discursive extension. This is precisely why Husserl puts in quotation marks the term "object" in "new 'object", which appears to us "in its very selfhood in a founded act"21. He clearly emphasizes the specificity of the notion of objectivity with-

21 It is also important to notice that, in the German original, not only is the term object - „Gegenstand", in quotation marks, but also that the words translated into English as "apprehension" - 
in the jurisdiction of newly founded acts, as irrevocably contrasted with the notion of an object in the process of the "unity of identification" where "the intention of serially arranged acts coincides continuously, and [...] the unity arises" (Husserl, 2006, 285). Husserl even differentiates between the unity of identification and the unity of an act of identification. However, we must also notice that the usage of the word "object" is not coincidental. Though it is clearly parenthesized, it is deliberately used so that the "synthetical work" obtained within the foundationalist frame of sensuous intuition is acknowledged as a necessary component that will be re-articulated within the realm of the categorial act. Although we are dealing, within the context of categorial acts, with "objects which can only show themselves 'in person' in such founded acts", these new "objects" are "also" "based on the older ones, they are related to what appears in the basic acts" (Husserl, 2006, 283). The "two-fold" referentiality is reflected (and "resolved") in the charge built into the self-evident extension of the realm of the categorial. This is precisely the reason why Husserl declares that the self-givenness of the universal can be only apprehended and furthermore, beheld (the German verbs are erfassen and erschauen). By emphasizing the constant charge and tension of self-extension as a self-execution, Husserl points out the importance of circular argumentation in a more resolute way.

As Jay Lampert emphasizes, the only accomplishment of the categorial realm is embodied in the fact that it needs to "count back" in order "to see how far it has come" (Lampert, 1995, 186). Lampert even goes so far as to say that "even though no single experience may be absolutely immediate or complete, both end-point and starting-point are presupposed as prior" (Lampert, 1995). We can therefore successfully avoid talking about "the results of synthesis" only because the absence of this result "takes the form of being posited in order for individual contents to be named, placed in context, put in perspective and epistemologically pursued " (Lampert, 1995, 186-187). Therefore, "it is precisely this absence of results that allows synthesis to have results" (Lampert, 1995, 187). In the following passage, Lampert captures the peculiarly tense dynamic that underlies the self-explicatory approach exercised by Husserl throughout $L I$ :

The ongoing mechanisms of synthesis, then, are cognition's self-critique. The content of an act of consciousness cannot be named without being contextualized, cannot be con-

selbst erfaßt and as "givenness" - gegeben. Also the word "apprehension" can be translated here in the reflexive context as an act of self-grasping performed (as much as its givenness) by the "object": "Der Akt der Identifizierung ist in der Tat ein neues Objektivitätsbewußtsein, das uns einen neuen ,Gegenstand' zur Erscheinung bringt, einen Gegenstand, welcher nur in einem fundierten Akt dieser Art , selbts erfaßt' oder, gegeben' sein kann" (Husserl, 1980, 151). 
textualized without passing through ordered perspectives, cannot be viewed in perspective without referring forwards to a limit-point, and cannot refer forward to a limit point without being a backward referent and in turn referring backwards and then forwards to the processes of its own history. The meaning of each content $i s$ in a sense independent of its precedents and successors, but only because the internal demands for self-explication that ground its necessary unity with the whole also set in motion systems of differentiations . [...] The system of all the systems of synthetically ordered experience has as its source-point the forward and backward references carried out in every single act of synthesis. (Lampert, 1995, 194)

Just as the inherent necessity of self-explication makes "the meaning of each [analytical] content" unique and independent of precedents and successors. So too the indisputability of self-unfolding underlies the specificity of every analytical unit or step in LI. Only by having in mind the structural obviousness of the underlying strategy of circularity are we able to conclude, with Lampert, that the system of all systems is precisely legitimized and confirmed in the exhibition of the unstoppable self-enclosure of its single points.

We can suggest that Husserl does not simply dismiss the notions such as synthetic unity or epistemological hierarchy, but that he radically rearticulates them apropos their role and constitutive components. The categorial unfolding is delineated as the process of its constant self-articulation, precisely through the re-articulation of how categoriality is conceived within the philosophical traditions Husserl was responding to. Similarly, we notice that Kant's seeming reconciliation of rationalism and empiricism demonstrates itself as a radical re-articulation of these philosophies rather than their overcoming or mere dismissal. The regulatory capacity of the realm of categorial is achieved through the procedural recognition of the results achieved within its preceding stages, not as the subsumption or the abolishment of these results. The division between the capacities of reason and its pure forms through their architectural mutuality is not only what sets the conditions for the subsequent establishment of transcendental philosophy, but is, in fact, the demonstration of that transcendental philosophy itself. The fact that the system and its correction can be seen through each other and as each other is made clear precisely through Kant's amplification of the fact that reason's capacity for regulation needs to be seen through the lens of reason's self-regulation. 


\section{REFERENCES}

Brandt, R. (1995). The Table of Judgments: Critique of Pure Reason A 67-76; B 92-101. Atascadero: Ridgeview Publishing Company.

Husserl, E. (1980). Logische Untersuchungen, I, II/1, II/2. Tübingen: Max Niemayer Verlag.

Husserl, E. (2001). Logical Investigations, vol. 1. London, New York: Routledge.

Husserl, E. (2006). Logical Investigations, vol. 2. London, New York: Routledge.

Kant, I. (1968). Werke. Darmstadt: Wissenschaftliche Buchgesellschaft.

Kant, I. (1977). Prolegomena to any Future Metaphysics. Indianapolis: Hackett Publishing Company.

Kant, I. (1987). Critique of Judgment. Indianapolis, Cambridge: Hackett Publishing Company.

Kant, I. (1998). Critique of Pure Reason. Cambridge: Cambridge University Press.

Kant, I. (2005). Notes and Fragments. Cambridge: Cambridge University Press.

Krüger, L. (2005). Did Kant Want to Prove the Completeness of His Table of Judgments. In T. Sturm et al. (Eds.), Why Does History Matter to Philosophy and the Sciences? Selected Essays (Quellen und Studien zur Philosophie, Band 66) (21-44). Berlin, New York: Walter de Gruyter.

Lampert, J. (1995). Synthesis and Backward Reference in Husserl's Logical Investigations. Dordrecht, Boston, London: Kluwer.

Reich, K. (1992). The Completeness of Kant's Table of Judgments. Stanford: Stanford University Press.

Tonelli, G. (1994). Kant's Critique of Pure Reason Within the Tradition of Modern Logic. New York: Georg Olms Verlag. 